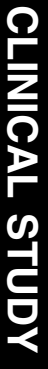

${ }^{1}$ Department of Ophthalmology, Chang Gung Memorial HospitalChiayi, Taiwan

${ }^{2}$ Department of Medicine, Chang Gung University College of Medicine,

Tao-Yuan, Taiwan

${ }^{3}$ Department of Ophthalmology, Chang Gung Memorial HospitalKaohsiung, Taiwan

${ }^{4}$ Department of Ophthalmology, Chang Gung Memorial HospitalLingko, Taiwan

${ }^{5}$ Department of Nursing, Chang Gung Institute of Technology, Chiayi, Taiwan

Correspondence: C-H Lai, Department of Ophthalmology, Chang Gung Memorial Hospital-Chiayi, Chiayi, 6, Sec West, Chia-Pu Road, Putzu, Chiayi 613, Taiwan Tel: + 88653621000 ext. 2580;

Fax: 88653623002 .

E-mails: oph4557@

cgmh.org.tw or oph4557gmail.com

Received: 26 February 2008 Accepted in revised form: 17 August 2008 Published online: 12 September 2008

The authors have no financial interest in any aspect of this study. This study was presented as a poster at Association for Research in Vision and Ophthalmology Annual Meeting, April 2008, Fort Lauderdale, FL, USA

\title{
Relationship of diabetic macular oedema with glycosylated haemoglobin
}

\begin{abstract}
Purpose To evaluate the correlation between glycosylated haemoglobin $(\mathrm{HbA1c})$ and central foveal thickness as measured by optical coherence tomography (OCT) in patients with diabetes.

Methods Retrospectively review of medical records of central foveal thickness as measured by OCT and laboratory data of glycosylated haemoglobin. HbA1c was compared with foveal thickness measured by OCT within the preceding 3 months. Clinically significant macular oedema (CSME) was diagnosed if central foveal retinal thickness was greater than $325 \mu \mathrm{m}$ in OCT.
\end{abstract}

Results One hundred and two eyes of 102 patients were included in this cross-sectional study. Univariate analysis revealed that the CSME diagnosed by OCT in diabetes was not statistically significant with sex, right or left eye, DM duration over 10 years or not, and AC sugar level (over 140 or not). The HbA1C level (8 or over) and age (50 or less) showed a significant ( $P=0.005$ and 0.006 , respectively) and positive association with macular thickness in OCT. A trend towards higher risk was seen for factors of age $\leqslant \mathbf{5 0}$ and HbA1c $\geqslant 8 \%$.

Conclusions Patients with HbA1c of 8 or above had an increase in macular thickness in type 2 diabetic eyes and there was a statistical significant correlation between younger age, shorter DM duration and thicker macular thickness. Strict sugar control decreased the risk of diabetic macular retinopathy, and OCT could be an excellent detector of early diabetic macular oedema.

Eye (2009) 23, 1360-1363; doi:10.1038/eye.2008.279; published online 12 September 2008
T-H Chou ${ }^{1,2}, \mathrm{P}-\mathrm{C} \mathrm{Wu}{ }^{2,3}, \mathrm{JZ}-\mathrm{C} \mathrm{KuO}^{2,4}, \mathrm{C}-\mathrm{H} \mathrm{Lai}^{1,2,5}$ and C-N KuO ${ }^{1,2}$
Keywords: diabetic macular oedema; glycosylated haemoglobin; optical coherence tomography

\section{Introduction}

Diabetic retinopathy (DR) is one of the complications of diabetes mellitus (DM) that causes most suffering. It is the leading cause of blindness in working-age adults. Diabetic macular oedema (DME), characterized by increased vascular permeability and deposition of hard exudates at the central retina, can occur at any stage of DR. DME is the main cause of poor visual acuity in patients with diabetes. In the past, DME was diagnosed by ophthalmoscope as clinical significance macular oedema. Fluorescein angiography is indicated in guiding treatment of macular oedema. ${ }^{1}$ With the help of optical coherence tomography (OCT), it is now possible to measure the macular thickness objectively and to follow the progression of DME quantitatively. ${ }^{2}$ Periodic glycosylated haemoglobin ( $\mathrm{HbA} 1 \mathrm{c})$ measurements can reflect the long-term control of hyperglycaemia. Intensive glycemic control had been proved to be effective in decreasing incidence rate of development and progression of DR in type 1 and type 2 diabetic mellitus as demonstrated by the diabetes control and complications trials ${ }^{3}$ and the United Kingdom Prospective Diabetes Study. ${ }^{4}$

To our knowledge, no published study at present has evaluated the relationship between macular thickness (measured by OCT) and long-term glycemic control (demonstrated by glycosylated haemoglobin). The purpose of this study is to evaluate the correlation between $\mathrm{HbA1c}$ and central foveal thickness measured by OCT in patients with diabetes. 


\section{Materials and methods}

This study is a retrospective review of medical records. Patients who were examined between December 2004 and July 2007 and had diagnoses of type 2 diabetes and pre-proliferative DR were identified through medical records. Eligible subjects had to meet all of the following criteria: (1) received complete ophthalmic evaluation; (2) had $\mathrm{HbA1c}$ measured by specific highpressure liquid chromatography methods; and (3) received OCT examination (Stratus OCT 3, Carl Zeiss Meditec, Dublin, CA, USA) within 3 months preceding HbA1c measurement. OCT was performed in both eyes, but the eye with thicker macular oedema was used for statistical analysis. Exclusion criteria included patients who received intraocular surgery (cataract surgery, pars plana vitrectomy, intravitreal injection of triamicinolone or Bevacizumab), subtenon injection, or photocoagulation therapy within 1 year of evaluation and severe vitreous haemorrhage or vitreous opacity that would interfere with the OCT examination. Clinically significant macular oedema (CSME) was diagnosed according to central macular retinal thickness greater than $325 \mu \mathrm{m}$ in OCT. ${ }^{5}$ This study was approved by Chang Gung Memorial Hospital Institutional Review Board. All research procedures followed the tenets of the Declaration of Helsinki.

\section{Statistical analysis}

Data were analysed using $\chi^{2}$ test or Fisher's exact test (if the expected value was under 5) for the univariate analysis of factors associated with CSME. Probability values of $P<0.05$ were considered statistically significant. In addition, logistic regression was used to estimate odds ratios and 95\% confidence intervals for further independent variables. Variables that were significant at the $P \leqslant 0.2$ level in the univariate analysis were included in backward logistic regression analysis to select the final list of independent variables. All analyses were computed using SPSS software (v10.0, SPSS Inc., Chicago, IL, USA).

\section{Results}

One hundred and two eyes of 102 patients were included in this cross-sectional study. Sixty three patients were male and 39 were female. The mean age \pm SD was $62.3 \pm 8.1$ years (range, $40-77$ years). The mean DM duration was $11.2 \pm 5.5$ years (range, $1-30$ years). The mean value of $\mathrm{HbA} 1 \mathrm{c}$ was $7.8 \pm 1.4 \%$ (range, $5.1-12.1 \%$ ). The mean central retinal thickness was $257.1 \pm 79.3 \mu \mathrm{m}$ (range, 151-526 $\mu \mathrm{m}$ ).

Table 1 shows the distribution of possible risk factors for CSME diagnosed by OCT among patients with

Table 1 Univariate and multivariate logistic regression analysis of factors associated with OCT-based CSME in diabetic eyes

\begin{tabular}{|c|c|c|c|c|c|c|c|}
\hline \multirow[t]{2}{*}{ Factor } & \multirow[t]{2}{*}{ Definition } & \multirow{2}{*}{$\begin{array}{c}\text { No CSME } \\
(\mathrm{OCT}<325 \mu \mathrm{m}) \\
\text { No. }(\%)\end{array}$} & \multirow{2}{*}{$\begin{array}{c}\text { CSME } \\
(\mathrm{OCT} \geqslant 325 \mu \mathrm{m}) \\
\text { No. }(\%)\end{array}$} & \multicolumn{2}{|c|}{ Univariate analysis } & \multicolumn{2}{|c|}{ Multivariate analysis } \\
\hline & & & & OR $(95 \% C I)$ & P-value & OR $(95 \% C I)$ & P-value \\
\hline \multirow[t]{2}{*}{ Age } & $>50$ & $81(95.3)$ & $12(70.6)$ & 1.0 & \multirow[t]{2}{*}{$0.006^{*}$} & 1.0 & \multirow[t]{2}{*}{$0.008^{*}$} \\
\hline & $\leqslant 50$ & $4(4.7)$ & $5(29.4)$ & $8.4(1.9-35.7)$ & & $8.2(1.7-38.8)$ & \\
\hline \multirow[t]{2}{*}{ Sex } & Male & $52(61.2)$ & $11(64.7)$ & 1.0 & \multirow[t]{2}{*}{0.78} & & \\
\hline & Female & $33(38.8)$ & $6(35.3)$ & $0.9(0.3-2.5)$ & & & \\
\hline \multirow[t]{2}{*}{ Laterality } & Left & $49(57.6)$ & $11(64.7)$ & 1.0 & \multirow[t]{2}{*}{0.59} & & \\
\hline & Right & $36(42.4)$ & $6(35.3)$ & $0.7(0.2-2.1)$ & & & \\
\hline \multirow[t]{2}{*}{ DM duration (years) } & $<10$ & $26(30.6)$ & $8(47.1)$ & 1.0 & \multirow[t]{2}{*}{0.18} & 1.0 & \multirow[t]{2}{*}{0.166} \\
\hline & $\geqslant 10$ & $59(69.4)$ & $9(52.9)$ & $0.5(0.2-1.4)$ & & $0.92(0.8-1.0)$ & \\
\hline \multirow[t]{2}{*}{ AC sugar $(\mathrm{mg} / 100 \mathrm{ml})$} & $<140$ & $28(40.6)$ & $4(26.7)$ & 1.0 & \multirow[t]{2}{*}{0.315} & & \\
\hline & $\geqslant 140$ & $41(59.4)$ & $11(73.3)$ & $1.9(0.5-6.4)$ & & & \\
\hline \multirow[t]{2}{*}{ HbA1c $(8 \%)$} & $<8$ & $56(65.9)$ & $5(29.4)$ & 1.0 & \multirow[t]{2}{*}{$0.005^{*}$} & 1.0 & \multirow[t]{2}{*}{$0.013^{*}$} \\
\hline & $\geqslant 8$ & $29(34.1)$ & $12(70.6)$ & $4.6(1.5-14.9)$ & & $4.5(1.4-15.1)$ & \\
\hline
\end{tabular}

Abbreviations: DM, diabetic mellitus. HbA1c, hemoglobin A1c.

For age, 0 indicates $>50$ years and 1 indicates $\leqslant 50$ years. For sex, 0 indicates male and 1 indicates female. For laterality, 0 indicates left and 1 indicates right. For DM duration, 0 indicates $<10$ years and 1 indicates $\geqslant 10$ years. For AC sugar, 0 indicates $<140 \mathrm{mg} / 100 \mathrm{ml}$ and 1 indicates $\geqslant 140 \mathrm{mg} / 100 \mathrm{ml}$; For HbA1c, 0 indicates $<8$ and 1 indicates $\geqslant 8$.

*Indicates statistically significant $(P<0.05)$. 
diabetes and results of the univariate and multivariate analysis.

Univariate analysis revealed that the CSME diagnosed by OCT in diabetes was not statistically significant with sex $(P=0.78)$, right or left eye $(P=0.59)$, DM duration over 10 years or over $(P=0.18)$, and AC sugar level (over 140 or not) $(P=0.315)$. The HbA1C level ( 8 or over) and age (50 or less) showed a significant $(P=0.005$ and 0.006 , respectively) and positive association with macular thickness in OCT.

A trend towards higher risk was seen for factors of age $\leqslant 50$, DM duration $<10$ years, and $\mathrm{HbA} 1 \mathrm{c} \geqslant 8 \%(P \leqslant 0.2)$. These three variables were included in multivariate analysis. Two variables including age $\leqslant 50$ and $\mathrm{HbA} 1 \mathrm{c}$ $\geqslant 8 \%$ were independently associated with CSME in diabetic eyes. HbA1c of 8 or over was associated with an increased risk of CSME in diabetic eyes (adjusted odds ratio, 4.5; 95\% confidence interval, 1.4-15.1, $P=0.013$ ). Age of 50 or less was associated with increased risk of CSME in diabetic eyes (adjusted odds ratio, 8.2; 95\% confidence interval, $1.7-38.8, P=0.008$ ).

\section{Discussion}

The incidence of type 1 diabetes is highly variable among different ethnic populations. ${ }^{6}$ It is especially lower in Chinese. The overall age-adjusted incidence of type 1 diabetes is $0.1-4.6 / 100000$ per year in China. ${ }^{7}$ In our study, there were two type 1 diabetes patients in 104 eligible subjects. To prevent from statistical bias, only type 2 diabetes patients were included in our study.

In the Wisconsin epidemiologic study of DR, the incidence of macular oedema over the 10-year period was associated with higher levels of glycosylated haemoglobin and more severe retinopathy in both younger- and older-onset groups. ${ }^{8}$ In our study, only mild-to-moderate DR was included, as severe cases were treated either by grid laser or intravitreal injection of triamicinolone or bevacizumab. It may explain that the shorter DM duration ( $<10$ years) is associated with macular oedema in our study.

Intensive glycemic control is associated with the development and progression of DM retinopathy. $\mathrm{HbA} 1 \mathrm{c}$ of 8 or above increased the risk of macular oedema. Moreira et $a l^{9}$ also found that HbA1c was the only variable that showed a significant association with macular oedema.

Periodic $\mathrm{HbA} 1 \mathrm{c}$ measurements could be of value in understanding the long-term glycemic control. OCT is a sensitive noninvasive diagnostic tool in the evaluation of macular oedema. OCT examination within 3 months preceding $\mathrm{HbA} 1 \mathrm{c}$ measurement may provide enough information about dynamic state of macular oedema and transitory glycemic control.
In our study, there is no significant linear correlation between the values of macular thickness and HbA1c. Hee et $a l^{10}$ also found that OCT values of foveal thickness between 200 and $325 \mu \mathrm{m}$ often disagreed with slit-lamp examination results of CSME. Therefore, CSME was diagnosed when central macular retinal thickness was greater than $325 \mu \mathrm{m}$ of OCT values in our study.

Diabetic macular oedema is associated with increased vascular permeability and vitreous traction. Although fluorescein angiography provides a qualitative assessment of vascular leakage and could help to distinguish the aetiology of macular oedema, actual macular thickness is the greatest contributing factor to best-corrected visual acuity. ${ }^{11}$

Other reported risk factors of DME, including increased diastolic blood pressure, insulin use, nephropathy, cataract surgery, and panretinal photocoagulation, were not analysed in our study. Further prospective study may be indicated for evaluation.

In conclusion, patients with $\mathrm{HbA1c}$ of 8 or above had an increase in macular thickness as measured by OCT in diabetic eyes and there was a statistical significant correlation between younger age, shorter DM duration, and thicker macular thickness. Strict sugar control decreased the risk of diabetic macular retinopathy, and OCT could be an excellent detector of early DME.

\section{References}

1 Diabetic retinopathy. American diabetes association. Diabetes Care 1998; 21: 157-159.

2 Hee MR, Puliafito CA, Wong C, Duker JS, Reichel E, Rutledge B et al. Quantitative assessment of macular edema with optical coherence tomography. Arch Ophthalmol 1995; 113: 1019-1029.

3 The relationship of glycemic exposure (HbA1c) to the risk of development progression of retinopathy in the diabetes control: and complications trial. The Diabetes Control and Complications Trial Research Group. Diabetes 1995; 44: 968-983.

4 Intensive blood-glucose control with sulphonylureas or insulin compared with conventional treatment and risk of complications in patients with type 2 diabetes (UKPDS 33). UK prospective diabetes study (UKPDS) group. Lancet 1998; 352: 837-853.

5 Browning DJ, McOwen MD, Bowen Jr RM, O'Marah TL. Comparison of the clinical diagnosis of diabetic macular edema with diagnosis by optical coherence tomography. Ophthalmology 2004; 111: 712-715.

6 Atkinson MA, Eisenbarth GS. Type 1 diabetes: new perspectives on disease pathogenesis and treatment. Lancet 2001; 358: 221-229.

7 Karvonen M, Viik-Kajander M, Moltchanova E, Libman I, LaPorte R, Tuomilehto J. Incidence of childhood type 1 diabetes worldwide. Diabetes mondiale (DiaMond) project group. Diabetes Care 2000; 23: 1516-1526.

8 Klein R, Klein BE, Moss SE, Cruickshanks KJ. The wisconsin epidemiologic study of diabetic retinopathy. XV. The longterm incidence of macular edema. Ophthalmology 1995; 102: $7-16$. 
9 Moreira RO, Trujillo FR, Meirelles RM, Ellinger VC, Zagury L. Use of optical coherence tomography (OCT) and indirect ophthalmoscopy in the diagnosis of macular edema in diabetic patients. Int Ophthalmol 2001; 24: 331-336.

10 Hee MR, Puliafito CA, Duker JS, Reichel E, Coker JG, Wilkins JR et al. Topography of diabetic macular edema with optical coherence tomography. Ophthalmology 1998; 105: 360-370.

11 Sakata K, Funatsu H, Harino S, Noma H, Hori S. Relationship of macular microcirculation and retinal thickness with visual acuity in diabetic macular edema. Ophthalmology 2007; 114: 2061-2069. 